\title{
The role of phonophoresis in dyshpagia due to cervical osteophytes
}

\author{
Zeliha Unlu' \\ Sebnem Orguc ${ }^{2}$ \\ Gorkem Eskiizmir ${ }^{3}$ \\ Asim Aslan ${ }^{3}$ \\ Saliha Tasci' \\ 'Department of Physical Medicine \\ and Rehabilitation; ${ }^{2}$ Department \\ of Radiology; ${ }^{3}$ Department of \\ Otorhinolaryngology, Celal Bayar \\ University School of Medicine, Manisa, \\ Turkey
}

\begin{abstract}
Objective: Treatment of patients with anterior cervical osteophytes causing dysphagia includes conservative treatment with anti-inflammatory drugs, muscle relaxants, antibiotics, and an appropriate soft diet. Physical therapy with its advantages may be an alternative method in the treatment, which was not reported previously.
\end{abstract}

Case description: Phonophoresis therapy is applied in nine patients with dysphagia due to cervical osteophytes.

Results: The symptom of dysphagia regressed in various degrees in all patients after phonophoresis therapy.

Conclusions: Phonophoresis might be an alternative method for the non-steroidal anti-inflammatory drug (NSAID) treatment in patients with dysphagia due to cervical osteophytes.

Keywords: cervical, osteophyte, dysphagia, physical therapy

\section{Introduction}

Osteophytes of the cervical spine have been reported to be one of the rare causes of dysphagia despite their high prevalence of $20 \%-30 \%$ in the asymptomatic elderly population (Bone et al 1974).

Most authors advise conservative treatment with anti-inflammatory drugs, muscle relaxants, antibiotics, and dietary nutrition for patients with anterior cervical osteophytes and dysphagia or dyspnea (Deutch et al 1985; Srinavas and George 1999; Ozgocmen et al 2002). Such patients have some difficulty in swallowing the tablet forms of nonsteroidal anti-inflammatory drugs (NSAIDs) or steroids. Hence liquid forms are recommended to prevent local irritation and ulcerative effects of these drugs on the esophageal mucosa (Ozgocmen et al 2002).

Phonophoresis has been used successfully to deliver anti-inflammatory medication to inflamed subcutaneous tissues (Byl 1995; Bare et al 1996; Cagnie et al 2003). In addition, when using pulsed-wave ultrasound there is anti-inflammatory and analgesic non-thermal effects. It has been stated that phonophoresis of ketoprofen allows the attainment of higher local concentration; whereas systemic exposure was lower (Cagnie et al 2003). Phonophoresis with anti-inflammatory and local anesthetic agents is used in the management of pain and inflammation in musculoskeletal conditions such as epicondylitis, tendinitis, tenosynovitis, bursitis, and osteoarthritis. The technique is noninvasive, well tolerated and involves minimal risk of gastric injury. Phonophoresis can be an alternative way to deliver NSAIDs in patients with dysphagia. To our best knowledge, the role of phonophoresis on the management of dysphagia caused by cervical ostephytes has not been studied.

In this case report, we reported our observations after phonophoresis therapy in nine patients complaining with dysphagia due to cervical ostephytes.

\section{Case reports}

Nine patients with dysphagia because of cervical spondylosis were included in this report. 


\section{Examinations}

Plain radiographs of the cervical and thoracic spine showed a massive ankylosing ossification of the anterior longitudinal ligament suggestive of diffuse idiopathic skeletal hyperostosis (DISH) in seven cases. These radiographs were concurrent with spondylosis in other two cases. Magnetic resonance imaging (MRI) of the cervical spine and barium swallow studies was performed to search the presence of compression of the esophagus. These examinations showed cervical spurs at the ventral portion of the vertebral bodies protruding ventrally and compressing the esophagus (Figure 1). Endoscopic evaluations of the esophagus were also performed and were completely normal in all cases.

All blood work was within normal limits, including complete cell count and thyroid function testing, except hyperglycemia.

The severity of dysphagia was measured using a $10-\mathrm{cm}(100 \mathrm{~mm})$ visual analog scale (no trouble: 0 - can not swallow: 100). In addition, a five-grade Likert scale which was adaptated for dysphagia by us (none; slight; moderate; severe; very severe; or can not swallow) was used to assess severity of dysphagia.

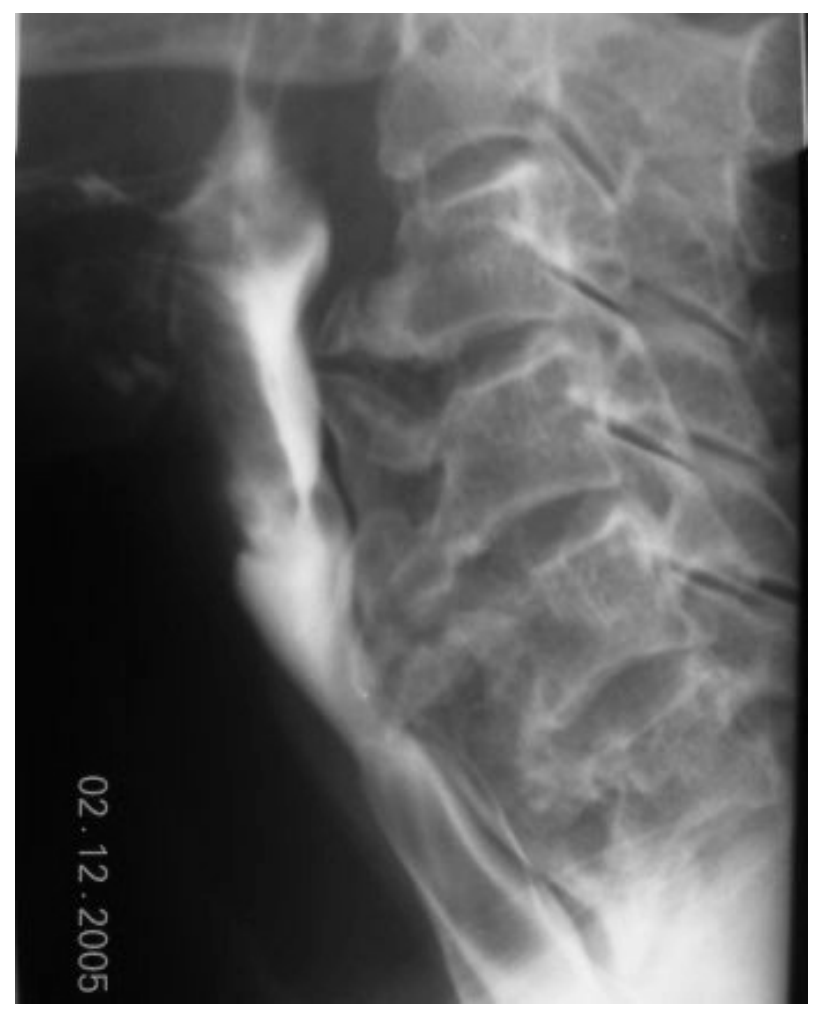

Figure I Barium swallow showing indentations on the esophagial lumen caused by anterior osteophyte formations and ossificated anterior longitudinal ligament more prominent at C3-4 and C4-5 levels.
Neck pain and disability were evaluated using the Neck Pain and Disability (NPAD) Scale (Wheeler et al 1999). Physical examinations of the cervical spine were performed. Cervical muscle tenderness was assessed using the total tenderness score method (Nilsson 1995). These two are reliable and valid measures of pain, disability and muscle tenderness.

\section{Treatment}

None of the patients received medical treatment, including analgesics and NSAIDs at least one month before the phonophoresis. Each patient received phonophoresis with a gel which contains a NSAID, ketoprofen. Phonophoresis was performed using a $1-\mathrm{MHz}$ Sonopuls 434 with a $5-\mathrm{cm}^{2}$ sound head at an intensity of $1.5 \mathrm{~W} / \mathrm{cm}^{2}$, pulse ratio of $2: 8$. Patients received phonophoresis at right and left sides of the posterior cervical region 5 days a week for 3 weeks for a total of 15 seances. The ultrasound head was moved over the gel using small, continuous, circular movements for 8 minutes (Forster and Palastanga 1985; Cagnie et al 2003). Treatment was applied by the same physiatrist (ST), who was blinded to clinical data and outcomes. Patients were instructed to eat soft foods and to chew well. Patients were assessed clinically before the treatment.

\section{Results}

The demographics of the patients and changes after the treatment are shown in Table 1. We observed either significant or minor improvements in the severity of dysphagia and cervical muscle tenderness of all the patients after treatment. There was reduction in disability and pain scores after the treatment.

\section{Discussion}

Osteophyte-induced dysphagia can be treated with NSAIDs and steroids with improvement of swallowing function by decreasing the amount of local inflammatory soft tissue (Ozgocmen et al 2002). However osteophyte-induced dysphagia may present a noninflammatory condition simply caused by compression of the esophagus by anterior osteophytes rather than by an inflammatory process. Nevertheless, the effect of anti-inflammatory treathments on dysphagia in these specific patients is uncertain due to limited exposure of cervical ostephytes with NSAIDs. Since pain and muscle spasm due to irritation by an osteophyte may be a factor in producing dysphagia (Sobol and Rigual 1984), we thought the analgesic effect of NSAIDs on pain and cervical muscle spasm might be more prominent 
Table I Characteristics of the patients and results of the therapy

\begin{tabular}{|c|c|c|c|c|c|c|c|c|c|c|c|}
\hline \multirow[t]{2}{*}{$\begin{array}{l}\text { Case } \\
(\mathrm{F} / \mathrm{M})\end{array}$} & \multirow[t]{2}{*}{ Age } & \multirow[t]{2}{*}{$\begin{array}{l}\text { Duration of } \\
\text { the dysphagia }\end{array}$} & \multirow[t]{2}{*}{ Weight loss } & \multicolumn{2}{|c|}{$\begin{array}{l}\text { Dysphagia severity } \\
\text { (VAS,mm) }\end{array}$} & \multicolumn{2}{|c|}{$\begin{array}{l}\text { Dysphagia severity } \\
\text { (Likert) }\end{array}$} & \multicolumn{2}{|c|}{ NPAD scale } & \multicolumn{2}{|c|}{$\begin{array}{l}\text { Cervical muscle } \\
\text { tenderness }\end{array}$} \\
\hline & & & & PreT & PostT & PreT & PostT & PreT & PostT & PreT & PostT \\
\hline $\mathrm{I} / \mathrm{M}$ & 68 & I year & None & 70 & 40 & 3 & 2 & 89.4 & 56.8 & 13 & 8 \\
\hline $2 / F$ & 62 & 6 months & $7 \mathrm{~kg}$ & 90 & 60 & 4 & 2 & 83.5 & 67 & 20 & 18 \\
\hline $3 / F$ & 73 & 3 years & None & 50 & 40 & 2 & 2 & 19.2 & 14 & 8 & 6 \\
\hline $4 / M$ & 80 & 3 months & None & 90 & 70 & 3 & 2 & 24.2 & 24 & 4 & 3 \\
\hline $5 / M$ & 56 & 2 years & None & 90 & 40 & 4 & 2 & 76 & 43.2 & 15 & 12 \\
\hline $6 / M$ & 49 & 3 years & None & 70 & 10 & 3 & 0 & 43.7 & 6.5 & 5 & 0 \\
\hline $7 / F$ & 57 & I year & None & 85 & 15 & 4 & I & 65.2 & 19.7 & 12 & 3 \\
\hline $8 / M$ & 77 & 3 years & None & 70 & 20 & 2 & 1 & 14 & II & 6 & 5 \\
\hline $9 / F$ & 68 & 5 years & None & 80 & 60 & 3 & 3 & 76.5 & 76 & 12 & 10 \\
\hline
\end{tabular}

Abbreviations: F, Female; M, Male; NPAD, Neck Pain and Disability (NPAD) Scale; PreT, Pretreatment; PostT, Posttreatment.

than the anti-inflammatory effect. On the other hand the adverse effects of steroids or NSAIDs on the esophageal mucosa must also be considered. From this perspective, phonophoresis is a superior alternative in the delivery of these drugs.

Following a total of 15 seances of phonophoresis with ketoprofen we observed improvements both in dysphagia and other cervical spine signs (Table 1). Both analgesic and anti-inflammatory effects of phonophoresis and pulsed-wave ultrasound on cervical pain and muscle spasm might be responsible for our beneficial results.

\section{Conclusion}

Ketoprofen phonophoresis seems to be a safe alternative treatment method in dysphagia due to cervical osteophytes. Although phonophoresis produced clinical improvement, further studies are needed to determine effectiveness of this treatment.

\section{Disclosure}

The authors report no conflicts of interest in this work.

\section{References}

Bare A, McAnaw M, Pritchard A. 1996. A phonophoretic delivery of $10 \%$ hydrocortisone through the epidermis of humans as determined by serum cortisol concentrations. Phys Ther, 76:738-49.

Bone RC, Nahum AM, Harris AS. 1974. Evaluation and correlation of dysphagia-producing cervical ostephytosis. Laryngoscope, 84:2045-50.

Byl N. 1995. The use of ultrasound as an enhancer for transcutaneous drug delivery: phonophoresis. Phys Ther, 75:539-53.

Cagnie B, Vinck E, Rimbaut S, et al. 2003. Phonophoresis versus topical application of ketoprofen: comparison between tissue and plasma levels. Phys Ther, 83:707-12.

Deutch EC, Shild JA, Mafee MF. 1985. Dysphagia and Forrestier's disease. Arch Otolaryngol, 111:400-2.

Forster A, Palastanga N. 1985. Clayton's Electrotherapy. London: Bailliere Tindall.

Nilsson N. 1995. Measuring cervical muscle tenderness: A study of reliability. J Manipulative Physiol Ther, 18:88-90.

Ozgocmen S, Kiris A, Kocakoc E, et al. 2002. Osteophyte-induced dysphagia: report of three cases. J Bone Spine, 69:226-9.

Sobol SM, Rigual NR. 1984. Anterolateral extrapharyngeal approach for clinical osteophyte-induced dysphagia. Literature review. Ann Otol Rhinol Laryngo, 93:498-504.

Srinivas P, George J. 1999. Cervical osteoarthropathy: an unusual cause of dysphagia. Age Ageing, 28:321-2.

Wheeler AH, Goolkasian P, Baird AC, et al. 1999. Development of the neck pain and disability scale. Spine, 24:1290-4. 
